\title{
Alkali Metal Mediated Resorcarene Capsules: An ESI-FTICRMS Study on Gas-Phase Structure and Cation Binding of Tetraethyl Resorcarene and its Per-methylated Derivative
}

\author{
Marko Mäkinen and Pirjo Vainiotalo \\ Department of Chemistry, University of Joensuu, Joensuu, Finland \\ Kari Rissanen \\ Department of Chemistry, University of Jyväskylä, Jyväskylä, Finland
}

\begin{abstract}
Electrospray ionization Fourier transform ion cyclotron resonance mass spectrometry (ESIFTICRMS) with additional ab initio calculations were used to examine the alkali metal cation binding selectivity (i.e., molecular recognition) and host properties of tetraethyl resorcarene (1) and its per-methylated derivative (2). The significance of intramolecular hydrogen bonding for the crown conformation was demonstrated. The presence of intramolecular flip-flop hydrogen bonding in $\mathbf{1}$ was confirmed both with calculations and in $\mathrm{ND}_{3}$-exchange experiments. All the alkali metal cations formed host-guest complexes by docking inside the cavity of the host. Complexation with the larger cations, especially $\mathrm{Cs}^{+}$, was favored. All the alkali metal cations also formed dimeric resorcarene capsules with $\mathbf{1}$. The capsules were directly H-bonded species, with no linking solvent molecules. $\mathrm{ND}_{3}$-exchange experiments and molecular modeling revealed the significance of direct intermolecular $\mathrm{H}$-bonding for the crown conformation of 1 and stability of the capsule structure. (J Am Soc Mass Spectrom 2002, 13, 851-861) ( 2002 American Society for Mass Spectrometry
\end{abstract}

A lthough resorcarenes [1] (also known as resorcinarenes) have been known for over a century, not until the 1990s were their unique properties examined in depth. The new interest is attributable to the development of advanced analytical methods and the diversity of applications now seen to be possible in chemistry and medicine, especially as regards hostguest chemistry. On the whole, resorcarenes are still less studied than the related calixarenes. In particular, few gas-phase studies on resorcarenes have been carried out by mass spectrometry.

Resorcarenes are prepared in relatively high yields via a simple one-pot synthesis [1]. Perhaps the most important of their several interesting and advantageous properties is the three-dimensional structure of parent alkyl resorcarene with its crown (occasionally called bowl) conformation. Other conformations are possible, but both in solid and liquid state the crown conformation appears to be the most stable for simple alkyl resorcarenes [2]. The cavity of resorcarene, the interior in the crown conformation, is formed by four aromatic

Published online June 11, 2002

Address reprint requests to Dr. P. Vainiotalo, Department of Chemistry, University of Joensuu, P.O. Box 111, 80101 Joensuu, Finland E-mail: pirjo.vainiotalo@joensuu.fi rings. The skeleton consists of two edges: A hydrophilic upper rim and a hydrophobic lower rim. The upper rim is formed of eight hydroxy groups at the wider side of the crown, while the lower rim is formed of alkyl (or aryl in some cases) chains attached to the methylene bridges between the aromatic rings. The methylene bridges and the internal $\mathrm{OH} \cdots \mathrm{H}$-bonding make the molecular skeleton relatively rigid. The intramolecular hydrogen bonding also explains the stability of the crown conformation [3]. Because of the rigidity of the macrocycle, it is only sparingly soluble in organic solvents and the melting point is high [4]. In addition, resorcarenes are strong $\mathrm{H}$-bond donors because the four hydrogens that are not participating in the intramolecular $\mathrm{OH}$...H-bonding system are pointing away from the cavity [5]. In alkaline conditions these four hydrogens are easily removed and the resulting tetra anion is extremely stable. The hydrogens participating in the intramolecular $\mathrm{OH} \cdots \mathrm{H}$-bonding system are not removed, however, even with $\mathrm{NaOH}$ treatment [6]. These and other features of the resorcarenes make them a very interesting and versatile class of macrocyclic compounds. Resorcarenes have recently been shown to serve as building blocks for self-assembled monolayers [7], to form ultra-thin film surface layers [8] and to act as host compounds [9]. They can also be used as building 


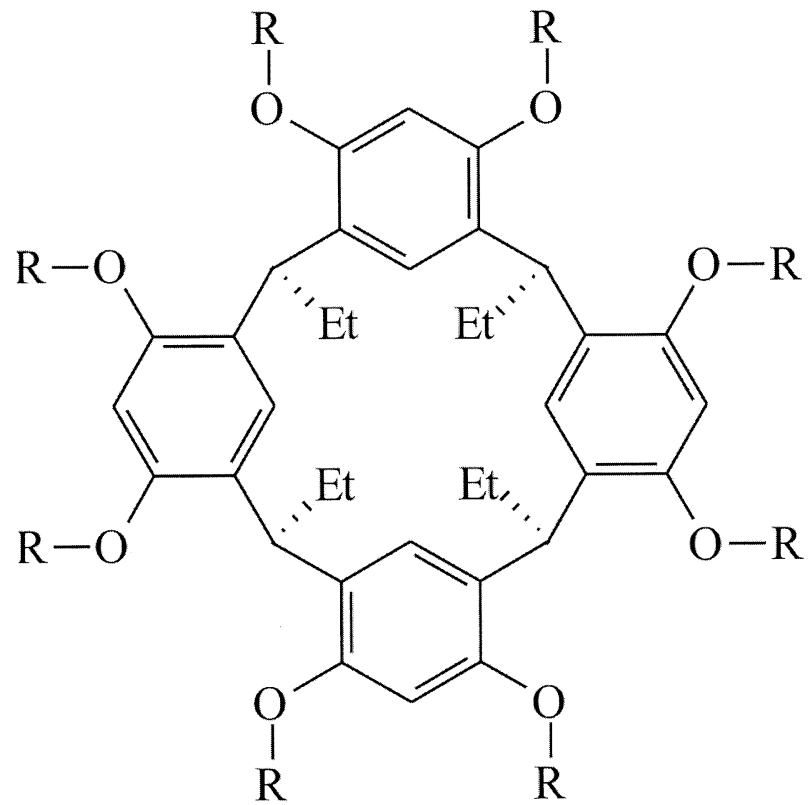

Resorcarene $\mathbf{R}$

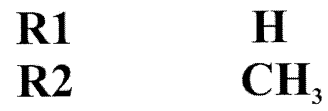

Figure 1. Structures of the resorcarenes.

blocks for larger supramolecular assemblies such as cavitands, carcerands and hemicarcerands [10], capsules [11], or even larger supramolecular assemblies [12].

The two resorcarenes investigated in this work are depicted in Figure 1. Compound $\mathbf{1}$ is tetraethyl resorcarene and Compound $\mathbf{2}$ its per-methylated analogue. Resorcarene 2 was included in the study to clarify the significance of the intra- and intermolecular hydrogen bonding features of $\mathbf{1}$. In the ESI-MS study performed to determine the general gas-phase properties of $\mathbf{1}$, a strong tendency was observed to form complexes with $\mathrm{Na}^{+}$and $\mathrm{K}^{+}$ion impurities, and in view of this it became of interest to measure the relative affinities (i.e., complex formation) of $\mathbf{1}$ and $\mathbf{2}$ towards alkali metal cations $\left(\mathrm{Li}^{+}, \mathrm{Na}^{+}, \mathrm{K}^{+}, \mathrm{Rb}^{+}, \mathrm{Cs}^{+}\right)$. All the alkali metal cations were studied in equimolar concentrations with the host in the sample solution. The amounts of the different alkali ion complexes were evaluated from the intensities of the respective peaks in the mass spectrum. The observation that mass spectrometric results really do correlate with the properties of the supramolecular species in solution has been provided by Schalley et al. [13]. Differences in the ionization efficiencies of the metal complexes and mass discrimination effects could conceivably pose a problem. According to Ralph et al. [14], however, ionization efficiency and mass discrimination effects are expected to be limited for inclusion complexes of a large host with a relatively small charged guest and can be neglected. Furthermore, the relative intensities of the peaks in the mass spectra due to these metal complexes parallel the trend in the stability constants [14]. Relative peak intensity ratios have also been used to estimate the cation binding selectivity of crown ethers [15] and calixarene derivatives [16]. The influence of the solvation energy is clearly present in the case of the singly charged alkali metal ions, however, Leize et al. have reported that the ESI-MS yielded a true image of the proportions of different species of alkali metal complexes present in thermodynamical equilibrium in solution [17]. The structure of our complexes was studied by H/D exchange experiments using $\mathrm{ND}_{3}$ as a neutral reagent and the collision-induced dissociation (CID) experiments were carried out to obtain information about the decomposition of the molecular monomeric and dimeric complexes.

Molecular modeling and ab initio calculations were performed to define the dimensions of the crown conformation of $\mathbf{1}$. The stabilizing effect of the intramolecular H-bonds between parallel resorcinol subunits was considered and calculated. The conformation of $\mathbf{2}$ was optimized by starting from the minimum energy conformation of $\mathbf{1}$. Also the structures of the sodium monomers of $\mathbf{1}$ and $\mathbf{2}$ were optimized. Finally, the structure of the dimeric sodium capsule containing two molecules of $\mathbf{1}$ and one sodium cation, [2M $+\mathrm{Na}]^{+}$, was optimized to give a probable structure of the capsule.

\section{Experimental}

\section{Samples}

The X-ray structure and characterization of $\mathbf{1}$ has been reported earlier [3] and 2 will be reported elsewhere. All commercial solvents and reagents were used without additional purification. All solvents were HPLC grade and were purchased from Sigma-Aldrich, Gillingham, UK. The stock solutions of $\mathbf{1}$ and $\mathbf{2}$ were made by dissolving them in acetonitrile and chloroform, respectively. Final sample solutions were made by methanol dilution, leading to final sample concentrations of 10 pmol $\mu \mathrm{l}^{-1}$ or lower. For the experiments on complex formation, all sample solutions contained a 1:1 ratio of host to guest. The alkali metal cations were introduced to the sample solution as chlorides diluted with water in equimolar concentrations. In competitive complex formation, isotope corrections were made to obtain the true amounts of cationic complexes.

\section{Equipment}

All mass spectrometry experiments were performed on the Bruker BioApex 47e Fourier transform ion cyclotron resonance (FTICR) mass spectrometer (Bruker Daltonics, Billerica, MA). This instrument is equipped with an Infinity cell, 4.7 tesla $160 \mathrm{~mm}$ bore superconducting magnet (Magnex Scientific Ltd., Abingdon, UK) and an 
external electrospray ion source (Analytica of Branford Inc., Branford, CT). The ultra high vacuum required $\left(5 \times 10^{-10}\right.$ torr in the cell) is accomplished by turbo pumps supplied by Edwards (Edwards High Vacuum International, Crawley, UK). Normal operating conditions were as follow: The sample was introduced through a syringe infusion pump (Cole-Parmer 74900 series, Cole-Parmer Instrument Company, Vernon Hills, IL) at a flow rate between 35 and $60 \mu \mathrm{l} \mathrm{h}^{-1}$; heated nitrogen $\left(225^{\circ} \mathrm{C}\right)$ was used as a counter-current drying gas. Ion source voltages were a constant $+3.5 \mathrm{kV}$ to cylinder and end plate. The capillary voltage was adjusted between +3.5 and $+5.0 \mathrm{kV}$; however, the usual value was $+4 \mathrm{kV}$. All the parameters were adjusted separately in each experiment to gain maximum signal intensity. The measurements were controlled by Bruker XMASS software version 5.0.6. Each spectrum was an average of 16 scans.

In CID experiments, collisionally cooled precursor ions were isolated in the ICR cell using the CHEF isolation technique [18]. The ions were activated and allowed to undergo collisions with pulsed argon gas and after $3 \mathrm{~s}$ dissociation delay time the spectrum was collected. In H/D exchange experiments, deuterated ammonia $\mathrm{ND}_{3}$ was introduced to the cell via a precision variable leak valve until the pressure in the cell was raised to $5 \times 10^{-8}$ torr. Ions were isolated as in the CID experiments and the monoisotopic isolated ions were allowed to react with neutral $\mathrm{ND}_{3}$ using reaction delay times from 1 to $30 \mathrm{~s}$.

\section{Theoretical Calculations}

$\mathrm{Ab}$ initio molecular orbital structure optimization calculations were made with a Gaussian 98 [19] using Hartree-Fock method and $6-31 \mathrm{G}++(\mathrm{d}, \mathrm{p})$ basis set for the hydroxyl groups of the resorcarene and 3-21G basis set for the rest of the molecular skeleton, exceptions are mentioned in the text. DFT calculations were made as single point energy calculations with B3LYP/6$31 \mathrm{G}++(\mathrm{d}, \mathrm{p})$ to the optimized structures from HF calculations.

\section{Results and Discussion}

\section{Mass Spectrometric Studies}

Basic spectra. Resorcarene $\mathbf{1}$ was preferably ionized by sodium cation. Ionization occurred in methanolic sample solution immediately when the cationic species was added. Sodium and potassium are common laboratory contaminants, and sometimes corresponding complexes were observed even without the spesific addition of these cations. The change of solvent from methanol to acetonitrile did not essentially alter the spectrum in any case, but usually complicated the experiments by causing signal weakening. When acetic acid was added to the sample solution for the purpose of obtaining the protonated species $[\mathrm{M}+\mathrm{H}]^{+}$, resorcarene 1 decom-

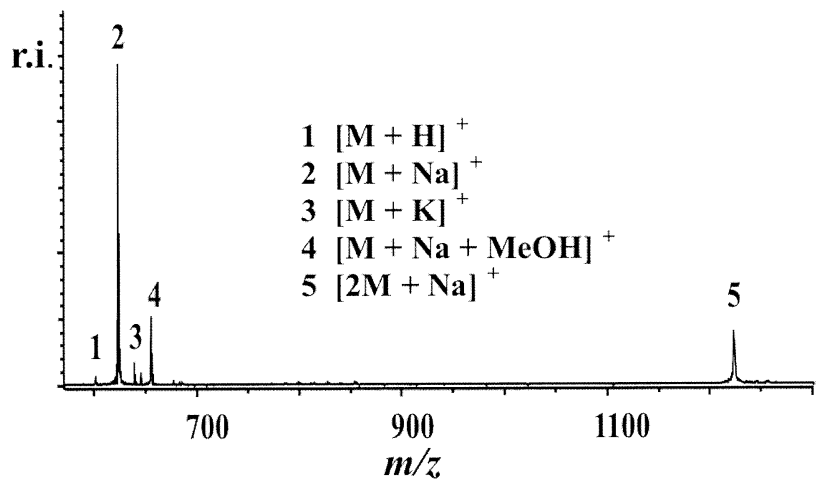

Figure 2. ESI-FTICR mass spectrum of resorcarene $\mathbf{1}$ with $\mathrm{Na}^{+}$.

posed and the spectrum that was recorded was difficult to interpret.

Figure 2 presents a typical ESI mass spectrum of $\mathbf{1}$. Only a minor amount of protonated molecule $[\mathrm{M}+\mathrm{H}]^{+}$ at $m / z 601$ is observed, and in several spectra the peak was absent. The most intense peak in the spectrum is that for the sodium adduct ion $[\mathrm{M}+\mathrm{Na}]^{+}$at $m / z 623$. As well, a complex including sodium and solvent molecule, $[\mathrm{M}+\mathrm{MeOH}+\mathrm{Na}]^{+}$, is observed at $m / z$ 655. There are two possible structures for this complex; either both methanol and sodium cation lie in the cavity of $\mathbf{1}$ or the sodium cation lies in the cavity while the methanol is H-bonded to the hydroxy groups of resorcarene and may point outside. This kind of H-bonding-based complex formation has been observed between resorcarene and some alcohols, primarily 1-butanol, in apolar organic media [20]. In our case, however, if the methanol solvent molecule were pointing outside it could be expected to evaporate during the ESI desolvatation process. It is more likely, therefore, that both the sodium cation and methanol are located, at least partially, inside the cavity of resorcarene and the methanol molecule avoids evaporation. Another finding supports this location: The ion $[\mathrm{M}+\mathrm{EtOH}+\mathrm{Na}]^{+}$was not observed in measurements of the corresponding ethanolic sample solution. Since the possibility to form H-bonds was there but the complex was not formed, evidently there was no $\mathrm{H}$-bonding holding the ethanol molecule outside the resorcarene cavity. From this we estimate that both the solvent molecule and the sodium cation are present inside the cavity of $\mathbf{1}$. Methanol and sodium cation are accommodated in the cavity of $\mathbf{1}$, but EtOH is too big to fit inside with the sodium cation. The peak at $\mathrm{m} / \mathrm{z} 639$ is derived from the ion $[\mathrm{M}+\mathrm{K}]^{+}$representing the potassium adduct. However, neither $[\mathrm{M}+\mathrm{MeOH}+$ $\mathrm{K}^{+}$nor other corresponding complexes with bigger cations were observed, evidently because of steric hindrance. It seems that when the size of either solvent or the cationic guest is large enough, the simultaneous complexation could not occur. The structure of the cationic monomeric complex is discussed in detail in the results section of the computational studies.

In addition to the monomeric species, also a dimeric species of $1,[2 \mathrm{M}+\mathrm{Na}]^{+}$, was observed at $\mathrm{m} / \mathrm{z} 1223$. A 
capsule structure was assumed, with the sodium cation inside. The structure of this capsule is discussed below. Also a potassium capsule $[2 \mathrm{M}+\mathrm{K}]^{+}$was present, detected at $m / z$ 1239. The intensities of the peaks representing capsules were usually about $20 \%$ of the peaks of the corresponding monomers, but they could be magnified through adjustment of the parameters. The formation of related dimers in ethanolic solutions has been reported earlier, although the origin of complexes was not explained [21]. Related to this, an NMR study has suggested the existence of hydrogen-bonded calixarene dimers in ethanol [22]. The possibility of dimeric complexes forming through an array of hydrogen bonds with solvent is also reported [23].

We assume that both the monomeric and dimeric complexes of $\mathbf{1}$ were formed in the methanolic sample solution, even though methanol is highly polar. Solvent-free gas-phase capsules may form in two ways: Directly in solution via intermolecular H-bonding between two resorcarene molecules without participation of solvent molecules or with linking of the resorcarene molecules via solvent molecules. In the latter case solvent free capsules could be formed during the ESI process as follows: During the desolvation process caused by heated drying gas both the surrounding solvent molecules and those linking the capsule evaporate. The electrostatic interactions between the two resorcarene molecules thereby strengthen and the proximity of the seemingly unconnected halves enable the formation of direct intermolecular hydrogen bonding and further, a gas-phase capsule. Whatever the formation mechanism, the forces holding the complexes together are strong enough to maintain the structure in vacuum. As will be shown later in this paper, the formation of the capsules appears to be disruptive of the intramolecular H-bonding network of the resorcarene subunit.

Occasionally a minor amount of trimeric sodium complex $[3 \mathrm{M}+\mathrm{Na}]^{+}$at $m / z 1823$ was observed. The detailed structure and significance of the 3:1 complexes are not discussed in this paper. Trimeric complexes have also been observed in interactions between alkali metal cations and crown ethers [24], and also an ESI-MS detection of even larger resorcarene-sodium clusters has been published [25].

The basic spectrum recorded from resorcarene 2 (molecular mass of $712 \mathrm{u}$ ) was simpler than that recorded from 1. Only monomeric complexes with sodium and potassium were observed. The failure of 2:1 complexes (capsules) to form demonstrates the significance of the OH-groups in the formation of capsules. Resorcarene $\mathbf{2}$ is unable to form such complexes because it lacks H-bonding donors.

The competitive sodium complex formation with $\mathbf{1}$ and $\mathbf{2}$ was studied by reacting equimolar amounts of $\mathbf{1}$ and 2 with added sodium. Monomeric complexes of both 1 and 2 were detected. The amount of the complex of 2 was considerably larger than the amount of complex of 1, i.e., the complex formation was more efficient with 2 . The probable reason is electrostatic: The methyl group is electron releasing [26] and thus intensifies the partial negative charge present in oxygens of the skeleton of 2 . The increased charge is more attractive to the cationic guests and complex formation with 2 is preferred over complex formation with 1. Another possibility is better steric fit. In addition, a heterodimeric sodium capsule $\left[\mathrm{M}_{1}+\mathrm{M}_{2}+\mathrm{Na}\right]^{+}$was formed. Resorcarenes $\mathbf{1}$ and $\mathbf{2}$ probably interact by H-bonding, $\mathbf{1}$ as $\mathrm{H}$-donor and $\mathbf{2}$ as acceptor, with possible additional help from the sodium cation stabilizing the structure by electrostatic forces.

Structure analyses. The structure of resorcarene 1 complex was probed in H/D exchange experiments and CID experiments. H/D exchange experiments with neutral $\mathrm{ND}_{3}$ in the FTICR cell were performed with the monomeric and dimeric sodium complexes of $\mathbf{1}$ to clarify the intramolecular H-bonding system. CID experiments, used to clarify the fragmentation pathway, were performed on the monomeric and the dimeric sodium complex of $\mathbf{1}$ and the heterodimeric sodium complex of $\mathbf{1}$ and 2.

Without an intramolecular H-bonding system the monomeric complex of $\mathbf{1}$ would have eight hydrogens available for exchange reactions with the deuterated reagent. With a circular $\mathrm{H}$-bond system, there would be four hydrogens not participating in the bonding and be available for exchange. The result of the H/D experiment was surprising: The monomeric sodium complex, depicted in Figure $3 \mathrm{a}$ after $30 \mathrm{~s}$ reaction time, did not exchange any hydrogens in the gas phase. A logical explanation of this result is the presence of directionvariable internal hydrogen bonding. The same phenomenon, detected by neutron diffraction in polysaccharides, is called flip-flop hydrogen bonding [27]. Intramolecular hydrogen-bond flipping has also been noted in recent article reporting for NMR results for calix [8] arenes [28]. It is claimed that flip-flop bridges are entropically favored over normal bonds because of the existence of two energetically almost equivalent states, and the H/D exchange occurs poorly when the flip-flop phenomenon is present [29]. Our results in $H / D$ exchange experiments are in accord with these earlier results and conclusions. Probably the rate of change in direction of hydrogen bonding is so high that formation of a stable enough collision complex is prevented and the deuterium exchange reaction becomes impossible. From this we conclude that the only possible gas-phase conformation is the crown, because it is the only conformation that allows a total intramolecular $\mathrm{H}$-bonding system between adjacent $\mathrm{OH}$-groups. The result of our $\mathrm{H} / \mathrm{D}$ experiment also implies that the cationic species inside the resorcarene crown does not interfere with the internal H-bonding system. Furthermore, the cavity present in the crown conformation explains the formation of complexes with all the alkali metal ions. When deuterated methanol $\mathrm{CD}_{3} \mathrm{OD}$ was used as solvent all the hydroxyl hydrogens were re- 

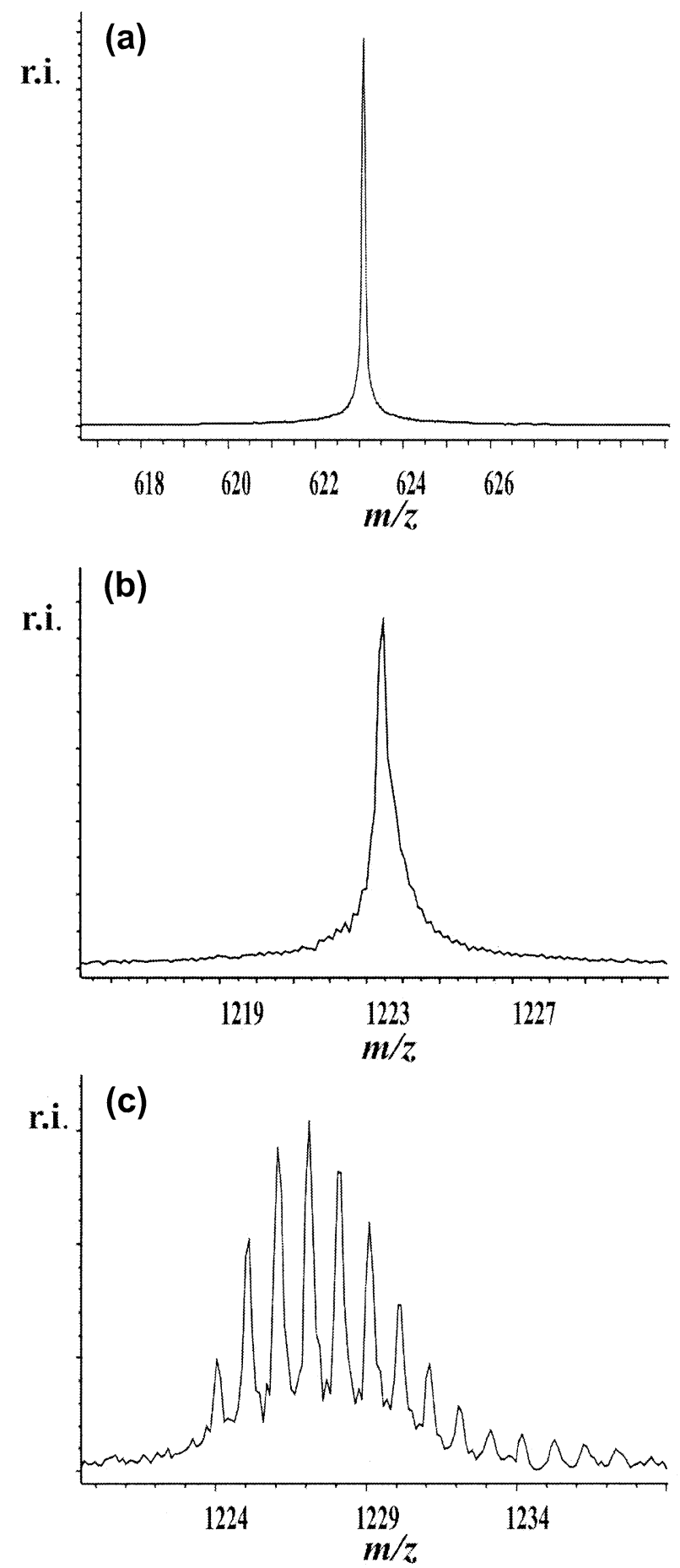

Figure 3. (a) H/D exchange spectrum of $\mathrm{Na}^{+}$monomer with $30 \mathrm{~s}$ delay. (b) Isolation spectrum of $1223 \mathrm{u}$. (c) H/D exchange spectrum of $\mathrm{Na}^{+}$capsule with $30 \mathrm{~s}$ delay.

placed with deuterium. This reactivity can be explained by the large excess of deuterated solvent and consequent possibility for multiple collisions and the long reaction time in the sample solution relative to the gas-phase experiment.

The gas-phase reactivity of the sodium capsule at $\mathrm{m} / \mathrm{z}$ 1223 with neutral $\mathrm{ND}_{3}$ was strikingly different from that of the monomeric sodium complex. The number of potential hydrogen exchanges here is 16 , corresponding to total H/D exchange. The H/D exchange spectrum of the sodium capsule recorded after $30 \mathrm{~s}$ reaction time is depicted in Figure 3c, and the monoisotopic isolation of the original capsule at $m / z 1223$ in Figure 3b. The figures show that the first eight hydrogens were exchanged much more easily than the remaining eight. This can be explained as follows: According to the calculations described below, four intermolecular hydrogen bonds are possible between the two resorcarene units in the capsule. Each of the hydroxyl groups participating in this $\mathrm{H}$-bond formation is also able to form a H-bond to the hydroxyl groups in the adjacent resorcinol moiety. These eight H-bonds are clearly static in nature, with no flip-flop movement. This allows the participating hydrogens to be exchanged with deuteriums even though the exchange is slow. (For example, after $15 \mathrm{~s}$ reaction time the base peak is $m / z 1224$, indicating the effective exchange of only one hydrogen.) The remaining four pairs of hydroxyl groups, two in each resorcarene unit, are still participating in intramolecular flip-flop movement, which strongly hinders their exchange with deuterium. However, the closeness of the two resorcarene molecules probably interferes with the flip-flopping of the hydrogens in the capsule, slightly slowing the movement compared to that in the monomeric complex, so that very low intensity exchange of the remaining eight hydrogens, totally absent in the monomeric complex, can occur.

CID experiments were performed on the monomeric and dimeric sodium complexes of $\mathbf{1}$ and the heterodimeric sodium complex of $\mathbf{1}$ and $\mathbf{2}$ to clarify the fragmentation pathways. The product ions detected for the sodium capsule with 1 were monomeric sodium complex at $m / z 623$ and the sodium cation $m / z 23$. When the sodium monomer was fully dissociated the only product ion was the sodium cation. This means that the energy needed to cleave the sodium is much lower than the energy needed to break the covalent bonds of the resorcarene skeleton. Because the cationic guests are bound by electrostatic forces weaker than covalent bonds, the result of the dissociation is a pure cationic species.

CID results for the heterodimeric sodium capsule were straightforward. Monomeric sodium complexes both of $\mathbf{1}$ and of $\mathbf{2}$ were observed, but the amount of the complex of 1 was near zero. When the capsule was dissociating, 2 preferably took the sodium cation. This is clearly seen in Figure 4. This result is in good agreement with the results obtained in the competitive experiments: The sodium affinity of $\mathbf{2}$ is much higher than that of $\mathbf{1}$.

Common to all CID experiments was the low value of the energy needed to dissociate the complexes. The reason for this low energy CID is simply that complexes are held together by non-covalent rather than covalent bonds. 


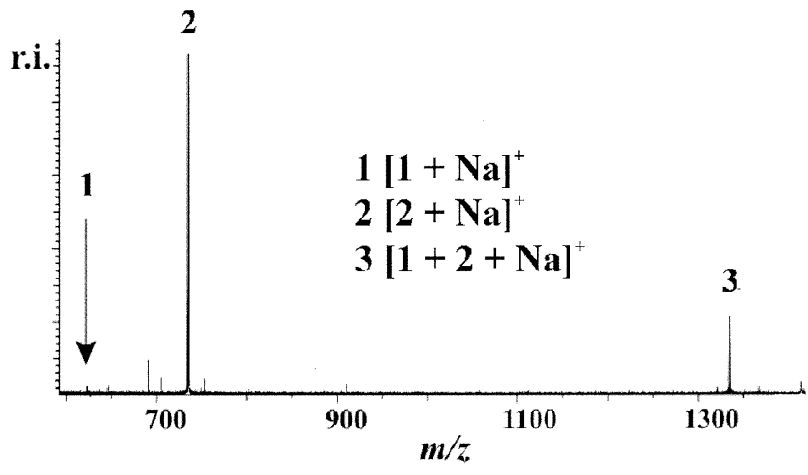

Figure 4. CID spectrum of heterodimeric sodium complex.

Competitive alkali metal complexation. As a means of determining possible cation binding selectivity and size-dependence of host-guest interactions between resorcarene and different cations, we added five alkali metal cations $\left(\mathrm{Li}^{+}, \mathrm{Na}^{+}, \mathrm{K}^{+}, \mathrm{Rb}^{+}, \mathrm{Cs}^{+}\right)$to the sample solutions of $\mathbf{1}$ and $\mathbf{2}$ in equimolar ratio. MS measurements were begun immediately and the amounts of the different complexes that were formed are seen in the corresponding peak intensities. Both monomeric and dimeric complexes were formed upon ionizing of the resorcarenes with alkali metal cations. Figure 5 depicts the spectrum obtained from the competitive complex formation. The relative amounts of complexes calculated from total ion current as an average of several experiments are shown in Figure 6.

Figure 5 shows the cation adduct monomers of 1 to be present in the $\mathrm{m} / \mathrm{z}$ area from 607 to 733 . Dimeric capsules are observed in the $m / z$ area 1207-1333. As can be seen, $\mathrm{Cs}^{+}$is the preferred guest. The usual overall order for the complexes that were formed was $\mathrm{Cs}^{+}>>$ $\mathrm{Rb}^{+}>\mathrm{K}^{+}>\mathrm{Na}^{+}>\mathrm{Li}^{+}$, which follows the volumes of the cations. Occasionally, the intensities observed for the $\mathrm{Rb}^{+}, \mathrm{K}^{+}$, and $\mathrm{Na}^{+}$complexes differed from this order owing to the presence of $\mathrm{K}^{+}$and $\mathrm{Na}^{+}$cations as

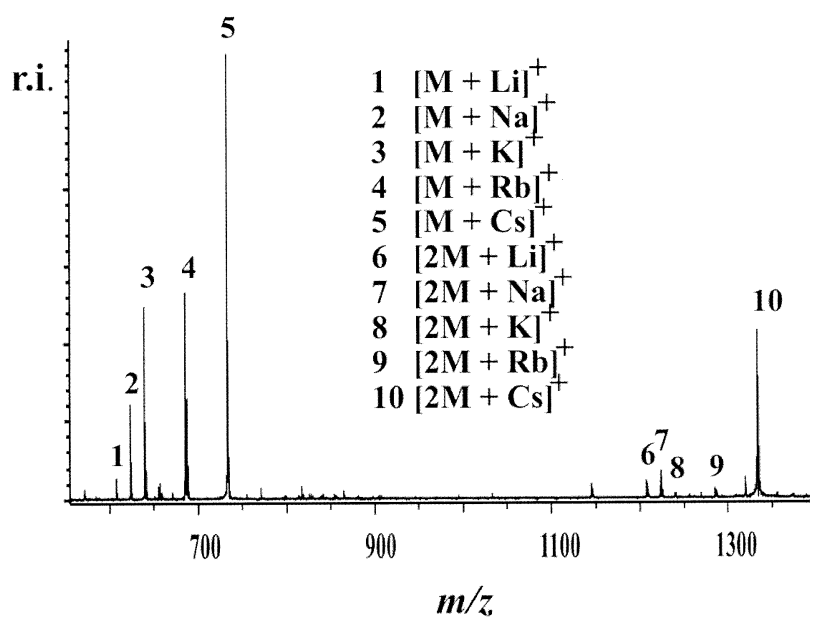

Figure 5. ESI- FTICR mass spectrum of $\mathbf{1}$ with all five alkali metal cations. The favorable binding of $\mathrm{Cs}^{+}$is clearly seen; both the monomer and the capsule complex of $\mathrm{Cs}^{+}$form the most intense peaks.

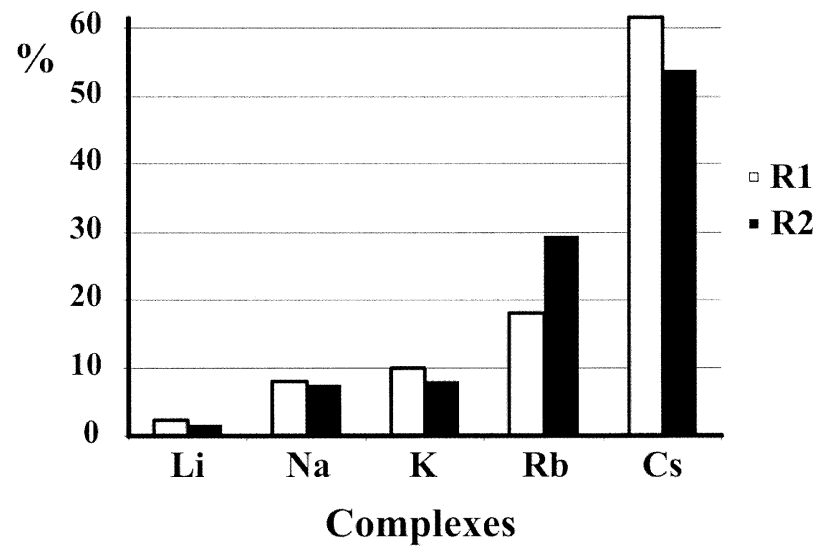

Figure 6. Relative amounts of alkali metal complexes with resorcarenes $\mathbf{1}$ and $\mathbf{2}$. Isotopic corrections are included.

laboratory contaminants. However, the $\mathrm{Li}^{+}$complex was always the minor one and the $\mathrm{Cs}^{+}$complex the major one. The difference in the intensities is great enough for us to conclude that $\mathbf{1}$ selectively binds $\mathrm{Cs}^{+}$. The order of the intensities become more pronounced when in-source CID was applied by increasing the capillary voltage. With increased voltage the energy of the complexes increases. All the monomeric complexes showed strong decomposition, but the decomposition of the $\mathrm{Cs}^{+}$complex was less drastic. The reason for this selectivity may be "steric fit" as has been shown for the crown ethers. The different size of the cations and the consequent differences in host-guest fitting characteristic are probably the main factors in governing their relative complex stabilities. In these complexes the empty space inside the resorcarene crown is smallest with $\mathrm{Cs}^{+}$ion. The lack of empty space is energetically favorable [30] and also the distances of non-covalent bonding interactions between cation and resorcarene cavity walls are decreased relative to the smaller cationic guests. Our ion complexation results are exactly the same than observed earlier to corresponding alkyl resorcarenes by the methods of foam fractionation and ion flotation [31].

The tendency of 2 was similar but monomers were the only species to form. Like $\mathbf{1}$, resorcarene 2 bound $\mathrm{Cs}^{+}$more abundantly than the other alkali metal cations. As in 1, the hosting was usually related to the volume of the guest. However, the selectivity for $\mathrm{Cs}^{+}$ relative to the to other cations was not as strong as with 1. The amounts of cationic complexes observed with 2 are shown in Figure 6.

\section{Computational Studies}

Orientation of the intramolecular H-bonding system. Some molecular modeling has been done earlier to calixarenes [32] and to resorcarenes [33]. The nomenclature for the different conformations of the resorcarene skeleton has been defined in literature [34]. The stereochemistry is defined by the conformation of the macrocyclic ring and 


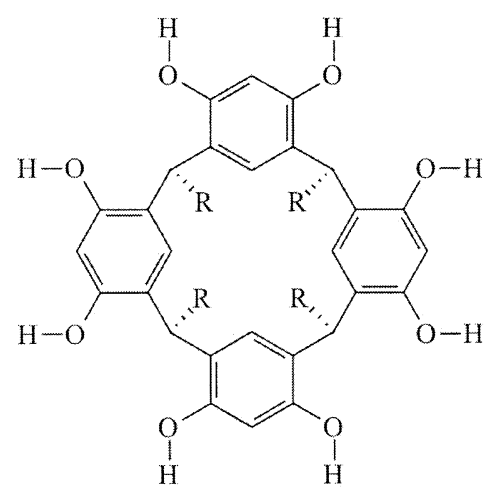

(a)

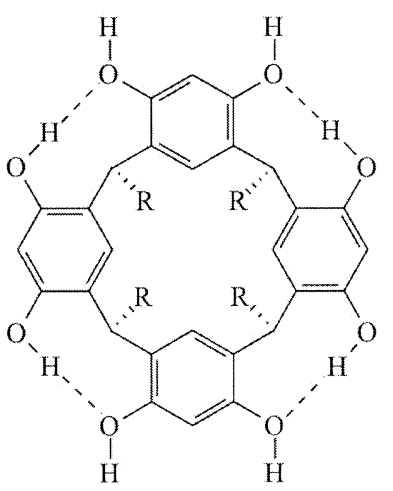

(b)

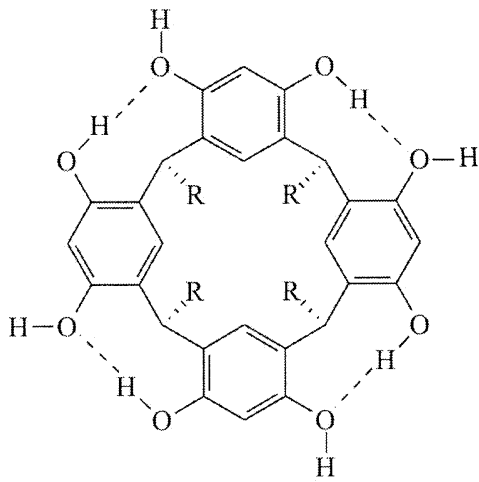

(c)

Figure 7. Orientations of the hydrogen bonds. H-bonds are marked with dotted lines. (a) $C_{2 \mathrm{v}}$ structure without internal H-bonding. (b) $C_{2 v}$ structure with oriented H-bonds. (c) $C_{4}$ structure with circular H-bonding network.

the crown conformation is found to be the most stable one both in the liquid and in the solid state. The purpose of the calculations was the consideration of the intramolecular H-bonding system. This was done to verify the different $\mathrm{H}$-bonding possibilities and their stabilizing influence on the resorcarene skeleton. Optimization calculations were made for the three possible crown structures depicted in Figure 7. Figure 7a is the structure without internal H-bonding system, which occurs when all the hydrogens present in the $\mathrm{OH}-$ groups are pointing "outside", i.e., there are no hydrogens between the oxygens. The optimization calculations severely bent the skeleton of $\mathbf{1}$, leading to interconversion near the boat conformation. Figure $7 \mathrm{~b}$ is the structure with $C_{2 v}$ symmetry when the hydrogen bonds are oriented; two opposite resorcinol units as $\mathrm{H}$-bond acceptors, and the other two units as H-bond donors. The directions of the $\mathrm{H}$-bonds were manually oriented before the optimization calculations. In this case, the calculation bent the skeleton moderately, and the result was a boat-like conformation with the possibility of directional H-bonding. Figure $7 \mathrm{c}$ has a circular $\mathrm{H}$-bonding network; each resorcinol unit is both an $\mathrm{H}$-bond donor and a $\mathrm{H}$-bond acceptor and the symmetry is $C_{4}$. The orientation could be either clockwise or anticlockwise; the clockwise one was manually constructed as a starting point for the calculations. The calculations did not damage the skeleton, and the orientation and interatomic distances still allowed a circular intramolecular H-bonding network between the adjacent OH-groups. The result is a "perfect" $C_{4}$ crown conformation.

The calculated energies are reported in Table 1. These energies obtained in ab initio calculations indicated that the $C_{4}$ symmetrical crown, which has four intramolecular H-bonds, is the most stable structure. The molecule with the boat conformation, $C_{2 \mathrm{v}}$ symmetry, and four oriented H-bonds is the next stable structure. The boat conformation without $\mathrm{H}$-bonding system had the highest energy value indicating the most un- stable conformational structure. From this it would seem that the intramolecular hydrogen bonding has a considerable stabilizating effect to the resorcarene skeleton and the crown conformation. Without stabilization, the crown conformation would twist and interconversions to other conformations would occur. Therefore, the skeleton may oscillate between two conformations. This kind of behavior has been reported earlier for resorcarene derivatives [35] and resorcarenes: NMR studies have shown that the average $C_{4 \mathrm{v}}$ structure symmetry is the result of two interconverting $C_{2 \mathrm{v}}$ boat conformers [36]. However, the rate of this change is so fast that severe conformational changes to the macrocyclic ring do not occur and the crown conformation is maintained.

In conclusion, the most favorable gas phase conformation of $\mathbf{1}$ is the crown, but the hydrogens may change their orientation. This kind of behavior has been reported earlier [27]. The situation can be explained by the nature of the intramolecular H-bonding network, which is actually formed from four (basicly) independent flip-flopping H-bonding "subsystems" between adjacent resorcinol units. Reorientation of the direction of the H-bonds is possible in each subsystem. This phenomenon also accords with the results of the H/D exchange experiments.

The calculated dimensions of the $C_{4}$ structure of 1

Table 1. Optimization calculation and single point calculation energies for the $\mathrm{H}$-bond systems of resorcarene $\mathbf{1}$

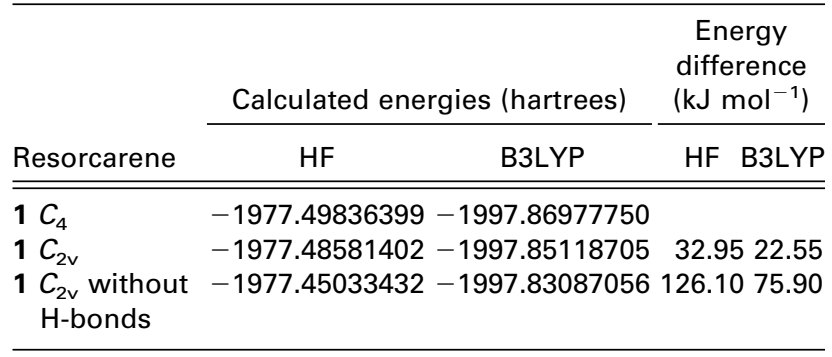



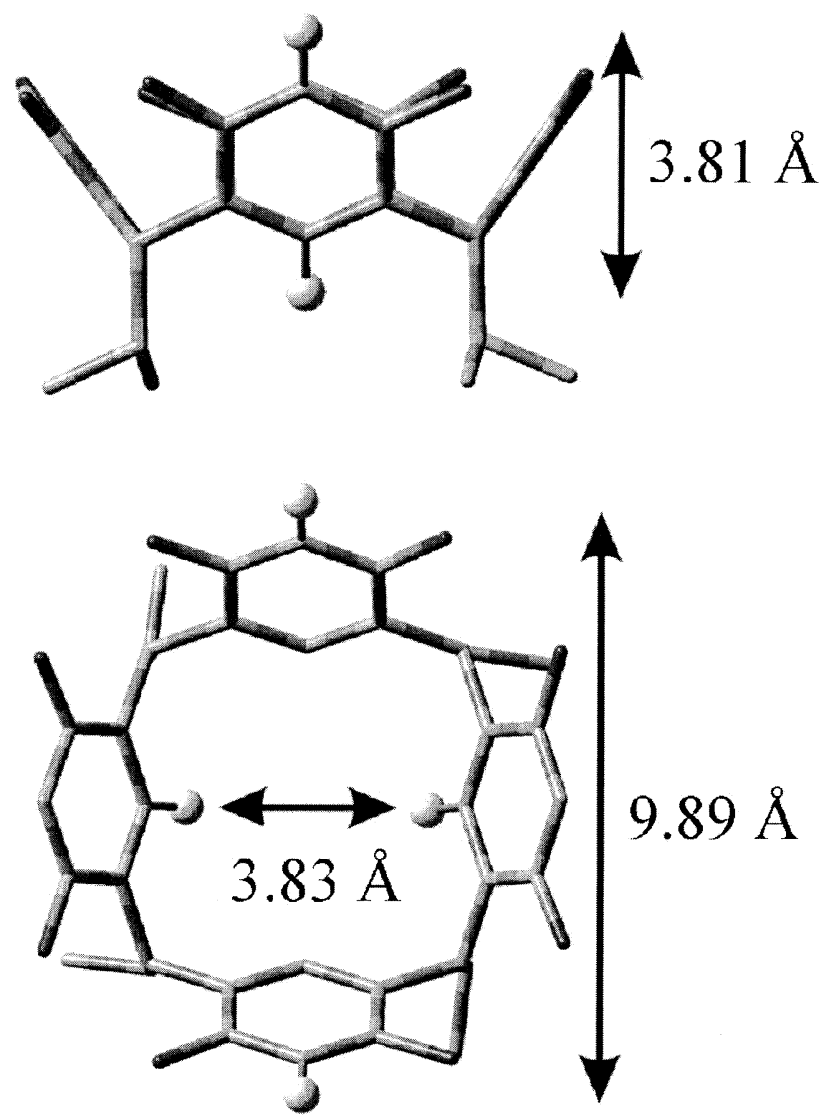

Figure 8. Optimized dimensions of the cavity of the resorcarene crown. (a) View from side. (b) View from above. The dimensions of the cavity are marked by hydrogen atoms, distances shown are $\mathrm{H}-\mathrm{H}$ internuclear distances.

are presented in Figure 8 . The levels of the phenyl and hydroxyl hydrogens form the imaginary rims of the cavity.

The situation with 2 is somewhat different. The optimization calculation (HF with 3-21G basis set) had an interconversion effect on the conformation. The starting point for the calculation was the crown conformer, but here there was no possibility for intramolecular hydrogen bonding and the change to the $C_{2 \mathrm{v}}$ boat conformation was inevitable. This conformation is similar to the conformation of $\mathbf{1}$ but without the $\mathrm{H}$ bonds (Figure $7 \mathrm{~b}$ ). On the basis of the similarity of the molecular skeleton to that of $\mathbf{1}$, this boat conformation was also assumed to be the most stable.

Resorcarene 2 also formed monomeric cationic complexes. The most propitious space for the guest was the interior of the skeleton between two parallel resorcinol units, i.e., the "broadsides" of the boat. The complex has minimum energy when the guest is located in the interior. As mentioned above, $\mathbf{2}$ is an even better host to $\mathrm{Na}^{+}$than is $\mathbf{1}$. One additional factor that may facilitate the complexation of $\mathbf{2}$ is easier accessibility of the cationic guests. The molecular skeleton of $\mathbf{1}$ could be described as a basket, and the only way the cation can enter is from above (or below). The conformation of 2 is more open, and the guest can also enter from the sides. Entry from the side is more likely with smaller guests. The probable reason for the greater affinity of $\mathbf{2}$ for sodium is the better steric fit provided by the boat conformation: The cleft formed by parallel resorcinols provides a much better platform for $\mathrm{Na}^{+}$to bind to than does the larger cavity of $\mathbf{1}$. In addition, conformational changes of the parallel resorcinol units of both $\mathbf{1}$ and $\mathbf{2}$ towards the sodium guest was also observed. Figure 9 depicts the optimized structures of the sodium complexes.

Capsules. The theory of guest-controlled formation of dimeric capsules has been reported for resorcarene derivatives: It is assumed that the cooperation of hostguest interactions and the intermolecular hydrogen bonding between resorcarenes leads to the formation of capsules [37]. A calculated (HF with STO-3G basis set) putative structure of the $\mathrm{Na}^{+}$capsule is depicted in Figure 10. It seems clear, therefore, that the intermolecular H-bonds between the two resorcarene crowns stabilize the capsule structure and promote the capsule formation process. According to calculation, four welldirected H-bonds are possible altogether. Although a single H-bond is rather weak, the cooperation between several H-bonds is sufficient to hold the capsule together in the gas-phase. According to calculation the sodium cation lies nearer to the lower rim in dimeric resorcarene than it does in the monomeric complex; it is not impossible, however, that it lies somewhere between the two resorcarene units and electrostatically binds them together. This might be still more plausible for larger cationic guest molecules. Therefore, the sodium cation can be a contributor to the stability of the capsule structure. Also the possibility of cation alternating between resorcarenes should not be ignored.

\section{Conclusions}

Mass spectrometry is a highly sophisticated technique for probing the properties of fragile non-covalently bonded host-guest complexes, providing as it does exact stoichiometric information on gas-phase aggregates of multiple species. In this ESI-FTICRMS study, alkali metal cations were employed as guests in complexation with two resorcarene hosts. Gas-phase H/D exchange experiments with neutral $\mathrm{ND}_{3}$ were made to test for the presence of a direction-variable hydrogenbonding network, so-called flip-flop hydrogen bonds, in resorcarene $\mathbf{1}$. In computational studies the conformations of the two host molecules were optimized to clarify the structures and electrostatic properties of the molecular skeletons, and additional calculations were made to clarify the phenomenon of host-guest complexation. The MS experiments and the calculations complemented each other: The molecular behavior of the complexes was clarified through a comparison of the MS and the calculated results. Optimization calculation 

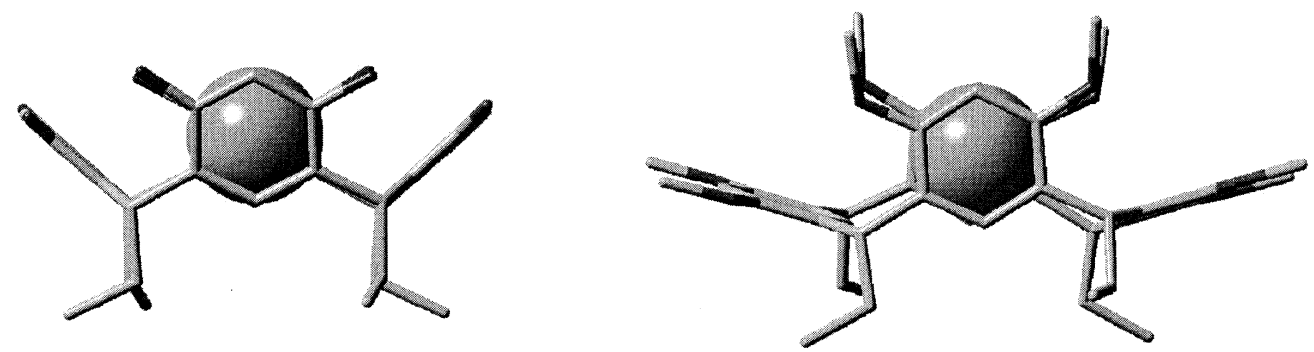

(a)

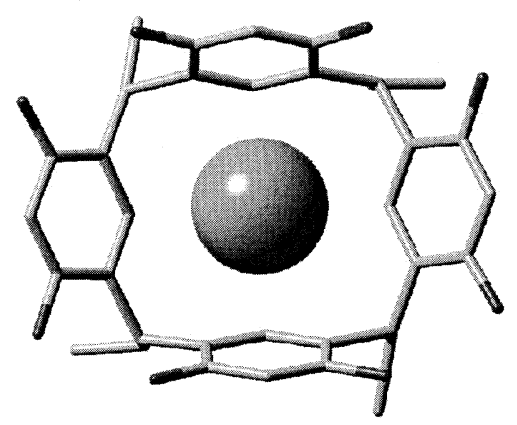

(b)

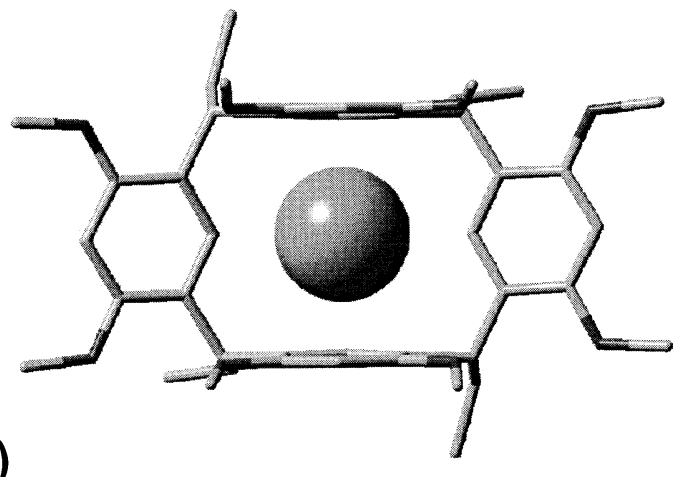

Figure 9. Optimized structures of sodium complexes 1 (left) and 2 (right). (a) View from side. (b) View from above. The hydrogens are omitted for clarity.

results, despite the limitations of the basic sets used, are in good accordance with the mass spectrometric results.

With resorcarene $\mathbf{1}$ the most stable conformation is the $C_{4}$ crown with a circular H-bonding network. Res-

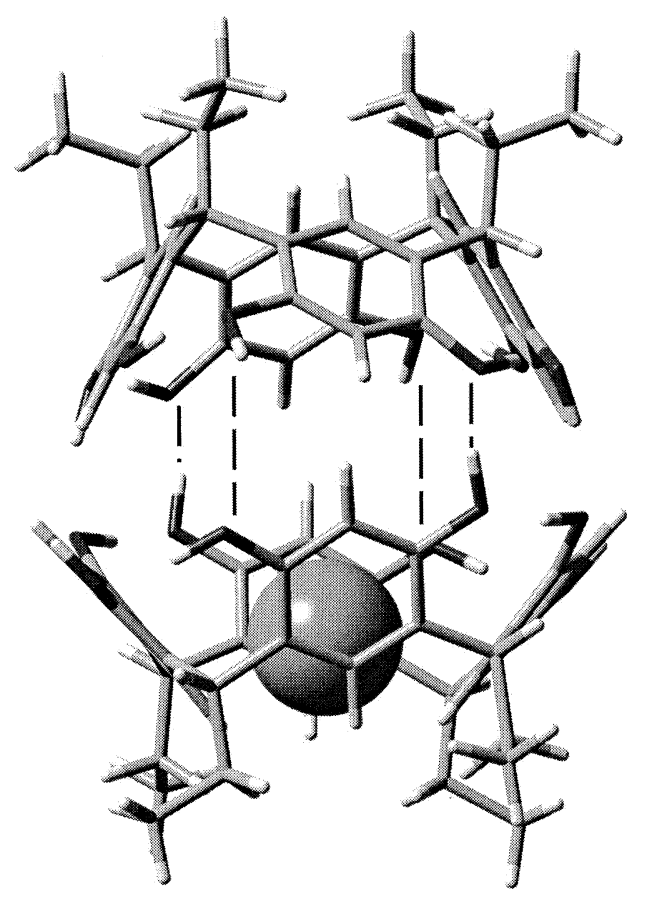

Figure 10. Optimized putative structure of the sodium capsule. H-bonds are marked with dotted lines. orcarene $\mathbf{2}$ has a totally different structure owing to the lack of internal H-bonding: Here the most stable conformation is the $C_{2 v}$ boat. This difference is reflected in the selectivity of the alkali metal cation binding. The experiments confirmed the capability of both resorcarenes to act as effective alkali metal cation hosts. The most stable conformation of resorcarene $\mathbf{1}$ has the $\pi$-basic cavity, which provides an excellent docking platform for guests of suitable size. The same applies to resorcarene 2, despite its different conformation. The partial negative charge in the upper rim of the resorcarenes assists the formation and presumably contributes to the stability of the complex through providing a stabilizing macrocyclic effect. Both resorcarenes exhibit a clear preference for the largest alkali metal cations. However, resorcarene 1 was more selective than 2 to $\mathrm{Cs}^{+}$, probably because its well-formed cavity provides lock-key opportunity for the complex formation. In a competitive situation, resorcarene $\mathbf{2}$ had the greater selectivity to $\mathrm{Na}^{+}$. Probably its more open conformational structure provides easier access so that the size of the cationic guest becomes less significant and the overall alkali metal cation selectivity is decreased relative to $\mathbf{1}$. The cationic species is located inside the host, thus forming a "genuine" host-guest complex.

Both calculations and H/D exchange experiments were consistent with the existence of a flip-flop hydrogen bonding network, as was observed earlier for cyclodextrins. The monomeric $\mathrm{Na}^{+}$complex of $\mathbf{1}$ was 
unable to exchange any of its hydroxyl hydrogens in the high vacuum of the FTICR cell, evidently because the fast change in direction of the direction-variable hydrogen bonding system impedes the formation of the stable collision complex necessary for the exchange to take place [38].

The existence of dimeric gas phase complexes, capsules, was observed for resorcarene $\mathbf{1}$ with all the alkali metal cations. To form the capsule, two resorcarene molecules are positioned with their upper rims facing each other. Some of the hydrogens form direct intermolecular H-bonds with the facing resorcarene molecule, without any solvent molecules linking the capsule. The calculation suggested that four well orientated intermolecular H-bonds hold the capsule together. The H/D exchange results confirmed the presence of both intraand intermolecular H-bonding systems. The hydrogens participating in the flip-flop movement are replaced only with difficulty, but the hydrogens forming static and directional hydrogen bonds can be replaced by deuterium. The fact that resorcarene 2 did not form capsules also underlines the significance of intermolecular H-bonding for the capsulation phenomenon. In addition, the heterodimeric capsule formation was observed. Although the mechanism by which the capsule forms is not entirely clear, the hypothesis that it involves assistance from the solvent is attractive. Such involvement of the solvent would also be of interest for our understanding of the desolvation process in electrospray ionization.

\section{Acknowledgments}

The authors thank Mr. J.-P. Jalkanen of the Department of Chemistry, University of Joensuu, for assistance and practical advice concerning the Gaussian 98 ab initio calculations, and Mr. D. Falábu of the Department of Chemistry, University of Jyväskylä, for synthesizing the compounds investigated. The authors gratefully acknowledge funding by the Academy of Finland, grant 68194 .

\section{References}

1. (a) Niederl, J. B.; Vogel, H. J. J. Am. Chem. Soc 1940, 62, 2512-2514 and references therein. (b) Högberg, A. G. S. J. Org. Chem 1980, 45, 4498-4500 and references therein.

2. (a) Konishi, H.; Morikawa, O. Chem. Commun. 1993, 34-35. (b) Abis, L.; Dalcanale, E.; du Vosel, A.; Spera, S. J. Chem. Soc. Perkin Trans. II 1990, 2075-2080. (c) Adams, H.; Davis, F.; Stirling, C. J. M. Chem. Commun. 1994, 2527-2528. (d) Leigh, D. A.; Linnane, P.; Pritchard, R. G.; Jackson, G. Chem. Commun. 1994, 389-390. (e) Aoyama, Y.; Tanaka, Y.; Sugahara, S. J. Am. Chem. Soc. 1989, 111, 5397-5404.

3. Nissinen, M.; Wegelius, E.; Falábu, D.; Rissanen, K. Cryst. Eng. Comm. 2000, 28, 1-3 and references therein.

4. Tunstadt, L. M.; Tucker, J. A.; Dalcanale, E.; Weiser, J.; Bryant, J. A.; Sherman, J. C.; Helgersson, R. C.; Knobler, C. B.; Cram, D. J. J. Org. Chem. 1989, 54, 1305-1312.

5. Konishi, H.; Morikawa, O. Chem. Express 1991, 10, 801-804.

6. Schneider, H-J.; Güttes, D.; Schneider, U. J. Am. Chem. Soc. 1988, 110, 6449-6454.

7. (a) Davis, F.; Stirling, J. M. Langmuir 1996, 12, 5356-5374. (b) Friggeri, A.; van Veggel, F. J. C. M.; Reinhoudt, D. N. Chem. Eur. J 1999, 5, 3595-3602.
8. (a) Davis, F.; Lucke, A. J.; Smith, K. A.; Stirling, C. J. M. Langmuir 1998, 14, 4180-4185. (b) Sugiyama, K.; Esumi, K.; Koide, Y. Langmuir 1996, 12, 6006-6010. (c) Dutton, P. J.; Conte, L. Langmuir 1999, 15, 613-617.

9. (a) Schneider, H.-J.; Schneider, U. J. Inclusion Phenom. Mol. Recog. 1994, 19, 67-83. (b) Fox, D.; Drew, M. G. B.; Wilkinson, E. S. J.; Beer, P. D. Chem. Commun. 2000, 391-392.

10. Cram, D. J.; Cram, J. M. Container Molecules and Their Guests. The Royal Society of Chemistry: Cambridge, 1994 Chap. V and references therein.

11. (a) Ma, S.; Rudkevich, D. M.; Rebek, J.,, Jr. J. Am. Chem. Soc. 1998, 120, 4977-4981. (b) Körner, S. K.; Tucci, F. C.; Rudkevich, D. M.; Heinz, T.; Rebek, J., Jr. Chem. Eur. J. 2000, 6, 187-195. (c) Conn, M. M.; Rebek, J., Jr. Chem. Rev. 1997, 98, 1647-1668. (d) Cho, Y. L.; Rudkevich, D. M.; Shivanyuk, A.; Rissanen, K.; Rebek, J., Jr. Chem. Eur. J. 2000, 6, 3788-3796.

12. (a) Timmermann, P.; Verboom, W.; van Veggel, F. J. C. M.; Van Hoorn, D.; Reinhoudt, D. N. Angew. Chem. Intl. Ed. Engl. 1994, 33, 1292-1295. (b) Chopra, N.; Sherman, J. Angew. Chem. Intl. Ed. Engl. 1997, 36, 1727-1729. (c) Fox, D.; Drew, M. G. B.; Beer, P. D. Angew. Chem. Int. Ed. Engl. 2000, 39, 135-140.

13. (a) Schalley, C. A.; Martín, T.; Obst, U.; Rebek, J., Jr. J. Am. Chem. Soc. 1999, 121, 2133-2138. (b) Schalley, C. A.; Castellano, R. K.; Brody, M. S.; Rudkevich, D. M.; Siuzdak, G.; Rebek, J., Jr. J. Am. Chem. Soc. 1999, 121, 4569-4579. (c) Schalley, C. A.; Rivera, J. M.; Martín, T.; Santamaria, J.; Siuzdak, G.; Rebek, J., Jr. Eur. J. Org. Chem. 1999, 1325-1331. (d) Schalley, C. A. Int. J. Mass Spectrom. 2000, 194, 11-39.

14. Ralph, S. F.; Iannitti, P.; Kanitz, R.; Sheil, M. M. Eur. Mass Spectrom. 1996, 2, 173-179.

15. (a) Wang, K.; Gokel, G. W. J. Org. Chem. 1996, 61, 4693-4697. (b) Bartoszek, M.; Graubaum, H.; Wendland, D.; Dambovski, R. Eur. Mass Spectrom. 1999, 5, 81-88. (c) Shou, W. Z.; Browner, R. F. Anal. Chem. 1999, 71, 3365-3373.

16. Virelizier, A. H.; Moulin, C. M.; Jankowski, C. K.; Dozol, J. F.; Tabet, J. C. Spectroscopy 2000, 14, 127-139.

17. Leize, E.; Jaffrezic, A.; Van Dorssaeler, A. J. Mass. Spec. 1996, $31,537-544$.

18. de Koning, L. J.; Nibbering, N. M. M.; van Orden, S. L.; Laukien, F. J. Int. J. Mass Spectrom. Ion Processes 1997, 165/166, 209-219.

19. Frisch, M. J.; Trucks, G. W.; Schlegel, H. B.; Scuseria, G. E.; Robb, M. A.; Cheeseman, J. R.; Zakrzewski, V. G.; Montgomery, J. A., Jr.; Stratmann, R. E.; Burant, J. C.; Dapprich, S.; Millam, J. M.; Daniels, A. D.; Kudin, K. N.; Strain, M. C.; Farkas, O.; Tomasi, J.; Barone, V.; Cossi, M.; Cammi, R.; Mennucci, B.; Pomelli, C.; Adamo, C.; Clifford, S.; Ochterski, J.; Petersson, G. A.; Ayala, P. Y.; Cui, Q.; Morokuma, K.; Malick, D. K.; Rabuck, A. D.; Raghavachari, K.; Foresman, J. B.; Cioslowski, J.; Ortiz, J. V.; Baboul, A. G.; Stefanov, B. B.; Liu, G.; Liashenko, A.; Piskorz, P.; Komaromi, I.; Gomperts, R.; Martin, R. L.; Fox, D. J.; Keith, T.; Al-Laham, M. A.; Peng, C. Y.; Nanayakkara, A.; Challacombe, M.; Gill, P. M. W.; Johnson, B.; Chen, W.; Wong, M. W.; Andres, J. L.; Gonzalez, C.; HeadGordon, M.; Replogle, E. S.; Pople, J. A. Gaussian 98, Revision A.9. Gaussian, Inc: Pittsburgh, 1998.

20. Kobayashi, K.; Asakawa, Y.; Kikuchi, Y.; Ayoama, Y. J. Am. Chem. Soc. 1993, 115, 2648-2654.

21. Gerkensmeier, T.; Iwanek, W.; Agena, C.; Fröhlich, R.; Kotila, S.; Näther, C.; Mattay, J. Eur. J. Org. Chem. 1999, 2257-2262.

22. Fukazawa, Y.; Deyama, K.; Usui, S. Tetrahedron Lett 1992, 33, 5803-5806.

23. (a) Rose, K. N.; Barbour, L. J.; Orr, G. W.; Atwood, J. L. Chem. Commun. 1998, 407-408. (b) Shivanyuk, A.; Rissanen, K.; Kolehmainen, E. Chem. Commun. 2000, 1107-1108. (c) Murayama, K.; Aoki, K. Chem. Commun. 1998, 607-608. 
24. Oshima, T.; Matsuda, F.; Fukushima, K.; Tamura, H.; Matsubayashi, G.; Arakawa, R. J. Chem. Soc. Perkin Trans. II 1998, 145-148.

25. Letzel, M. C. Agena C.; Mattay, J. Eur. J. Mass Spectrom. 2001, 7, 35-38.

26. Morrison, R. T.; Boyd, R. N. Organic Chemistry, 6th ed. Prentice Hall: Englewood Cliffs, 1992, pp 536-537.

27. (a) Saenger, W.; Betzel, C.; Hingerty, B.; Brown, G. M. Nature 1982, 296, 581-583. (b) Rudkevich, D. M. Chem. Eur. J. 2000, 6, $2679-2686$.

28. Tsue, H.; Ohmori, M.; Hirao, K. J. Org. Chem. 1998, 63, $4866-4867$.

29. (a) Saenger, W.; Betzel, C.; Hingerty, B.; Brown, G. M. Angew. Chem. Int. Ed. Engl. 1983, 22, 883-884. (b) Betzel, C.; Saenger, W.; Hingerty, B. E.; Brown, G. M. J. Am. Chem. Soc. 1984, 106, 7545-7557.

30. Chapman, R. G.; Sherman, J. C. Tetrahedron 1997, 53, 1591115945.
31. Koide, Y.; Oka, T.; Imamura, A.; Shosenji, H.; Yamada, K. Bull. Chem. Soc. Jpn. 1993, 66, 2137-2142.

32. (a) Grootenhuis, P. D. J.; Kollman, P. A.; Groenen, L. C.; Reinhoudt, D. N.; van Hummel, G. J.; Ugozzoli, F.; Andreetti, G. D. J. Am. Chem. Soc. 1990, 112, 4165-4176. (b) Thondorf, I. J. Chem. Soc. Perkin Trans. II 1999, 1791-1796.

33. Thondorf, I.; Brenn, J.; Böhmer, V. Tetrahedron 1998, 54, 1282312828 .

34. Timmermann, P.; Verboom, W.; Reinhoudt, D. N. Tetrahedron 1996, 52, 2663-2704.

35. Rudkevich, D. M.; Hilmersson, G. Rebek, J., Jr. J. Am. Chem. Soc. 1998, 120, 12216-12225.

36. Abis, L.; Dalcanale, E.; Du vosel, A.; Spera, S. J. Org. Chem. 1998, 53, 5475-5479.

37. Shivanyuk, A.; Paulus, E. F.; Böhmer, V. Angew. Chem. Int. Ed. 1999, 38, 2906-2909.

38. Harrison, A. G. Chemical Ionization Mass Spectrometry, 2nd ed. CRC Press: Boca Raton, 1992; p 171-174. 